\section{Osteopontin expression and calcium content in human aortic valves}

\section{To the Editor:}

The cause or causes of calcific aortic stenosis (CAS) remain unknown. A number of studies have suggested genetic factors, preexisting rheumatic inflammation, or osteopontin expression., ${ }^{1,2}$ Osteopontin is a calcium-binding glycoprotein ligand of CD44 surface receptor also present in fetal bone, teeth, and exocrine endothelial cells. The present study was undertaken to test the hypothesis that osteopontin and valve calcium content could be related to CAS.

We studied aortic valves from patients undergoing aortic valve replacement using monoclonal antibodies against osteopontin and $\alpha$-smooth muscle actin. In a prospective study, we evaluated 15 unselected patients aged 22 to 84 years (mean 58.4 years), of whom 10 were women, undergoing aortic valve replacement for valvular stenosis or regurgitation. Valve specimens were received in the operating room and preserved in ice during transportation; they were then stored at $-70^{\circ} \mathrm{C}$. A portion of the tissue was removed and fixed in aqueous Bouin solution for immunohistochemical study. Total calcium content (in micrograms per gram of dry tissue) was determined by $7 \mathrm{~N} \mathrm{HNO}_{3}$ digestion and atomic absorption spectroscopy.

After fixation in Bouin solution, the samples were embedded in paraffin. Four-micrometer transverse sections cut on a microtome at room temperature were stained for osteopontin (MPIIIB10 from the Developmental Studies Hybridoma Bank, University of Iowa, diluted 1:100, and Actin 1A4 from Sigma Chemical Company, St Louis, Mo) with an ABC-peroxidase kit (Vector Laboratories, Burlingame, Calif) and counterstained with hematoxylin. Sections were evaluated without knowledge of the tissue osteopontin expression or calcium content. Ten revealed calcification. Of these, 5 had fibrous thickening with calcification; the remainder were calcific AS of the senile type, but the presence of thick-walled vessels suggested postinflammatory valve disease. Five patients with uncalcified valves had fibrotic disruption of cusp architecture, associated with neovessels with thick muscular walls and few mononuclear inflammatory cells, consistent with postinflammatory (rheumatic) valve disease. Calcium content was $3091 \mu \mathrm{mol} / \mathrm{g}$ dry tissue (SE $=1048 \mu \mathrm{mol} / \mathrm{g}$ dry tissue) versus $359 \mu \mathrm{mol} / \mathrm{g}$ dry tissue $(\mathrm{SE}=297 \mu \mathrm{mol} / \mathrm{g}$ dry tissue $)$ (Wilcoxon signed-rank $\chi^{2}, P=.0004$ ).

Osteopontin expression was present in 9 of 10 calcified valves and 1 positive fetal femur in a control subject. It was restricted to the cytoplasm of fibroblast-like spindle cells, with a paranuclear granular locoalization, probably in the Golgi area. No osteopontin expression was noted in the 5 patients with uncalcified valves $\left(\chi^{2}=8.02, P<.005\right)$. Mohler and associates ${ }^{1}$ reported indentification of osteopontin in CAS $(n=5)$ and in noncalcified regurgitant valves $(n=3)$. Our results show that osteopontin and $\mathrm{Ca}^{2+}$ are directly associated with CAS, results differing from those of Mohler and colleagues. ${ }^{1}$ O'Brien and coworkers ${ }^{2}$ have shown that osteopontin messenger RNA can be produced by macrophages.

We thank Professor Philippe Menaché, Dr Philippe Chappuis of the Department of Biochemistry, and Dr Karen Jensen of the University of Iowa for their help in this study. The mouse osteopontin antibody was obtained from the Developmental Studies Hybridoma Bank maintained by the Department of Pharmacology and Molecular Sciences, Johns Hopkins University School of Medicine, Baltimore, Maryland, and the University of Iowa, Iowa City, Iowa, under contract NO1-HD-6-2915 from the National Institute of Child Health and Human Development (NICHD).

$$
\begin{array}{r}
\text { John H. Kennedy, } M D \\
\text { D. Henrion, } P h D \\
\text { M. Wassef } M D \\
\text { C. M. Shanahan, } M D \\
\text { G. Bloch, } M D \\
\text { A. Tedgui, PhD } \\
\text { Cambridge, United Kingdom, and Paris, France }
\end{array}
$$

\section{REFERENCES}

1. Mohler ER, McClelland P, Adam LP, Hathaway DR. Identification of bone morphogenic protein-2 and osteopontin in calcified aortic valves. Circulation 1994;90:1-52.

2. O'Brien KD, Kuusisto J, Reichenbach DD, Ferguson M, Giachelli CM, Alpers CE, et al. Osteopontin is expressed in human aortic valvular lesions. Circulation 1995;92:2163-8.

12/8/106968

doi:10.1067/mtc.2000.106968 